\title{
Alternative Perspectives on Orality, Literacy and Education: A View from South Africa
}

David H. Gough

School of Languages, Christchurch Polytechnic, PO Box 22095, Christchurch 8032, New Zealand

\section{Zannie Bock}

Department of Linguistics, University of the Western Cape, Private Bag XI7, Bellville 7535, South Africa

The question of the 'great divide' between orality and literacy has been critically addressed by various scholars of literacy, including social literacy theorists. This paper uses the notions of primary and secondary discourse across both oral and literate contexts to examine this 'divide'. Using evidence from the oral tradition of the Xhosa, it is shown that 'traditional' societies have well-established primary and secondary discourse types. Against this understanding, the issue of 'access' to Western academic literacy is examined. It is argued that within the changing context of South African society and as a direct result of former apartheid policies, individuals may have failed to acquire the cultural capital of both oral secondary and literate secondary discourse types. The literate secondary discourse practices of Xhosa-speaking students at university are explored through an analysis of student writing. This paper then reports on several projects which attempt to address some of the concerns of academic staff with respect to student writing. In particular, this section argues for a broadening of the notion of 'academic literacy' and suggests some ways in which texts derived from the oral tradition may be used to develop awareness of secondary discourse types.

\section{Introduction}

This paper is divided into three parts. In the first part we examine theoretical concerns about discourses associated with what has come to be referred to as the 'oral tradition' and discourses associated typically with academic contexts, in order to see how these may relate to students' experience of higher learning. We illustrate this by using examples from the Xhosa oral tradition. In the second part we take a look at particular features of the writing of our students, who are predominantly Xhosa speakers and analyse the kinds of discourses they seem to display. Thirdly, we report on some of the ways in which our department, the Department of Linguistics at the University of the Western Cape, South Africa, has responded to the challenges raised by this writing and outline possible projects for the future. 


\section{Theoretical Concerns}

\section{Discourse}

By discourse, we are referring to what Gee (1990: 150) defines as 'socioculturally determined ways of thinking, feeling, valuing, and using language' in different contexts in our day-to-day lives. We make a distinction between primary and secondary discourse. Primary discourse includes everyday conversational interaction and demands no degree of specialised knowledge or language as a prerequisite for participation. It is, in a sense, one's informal home discourse. Secondary discourse, on the other hand, is 'specialist' discourse. It requires a degree of expert knowledge and language to produce and comprehend and is something that is, in rather simplistic terms, learned and refined rather than acquired. These, of course, are not absolute distinctions, and there is clearly a continuum from primary to secondary discourse. At any one time, our interaction in language is situated along this continuum.

The distinction between concepts such as primary and secondary discourse is certainly not new. In the early part of the twentieth century Benjamin Lee Whorf, who was centrally concerned with the relationship between language and thought, made a similar distinction at the conceptual level between what he termed 'habitual' and 'specialised' thought, where we can relate the latter to secondary discourse, and the former to primary discourse. (See Lucy, 1992: 272-273 for a useful summary.) Much more recently, and simplifying his argument somewhat for the sake of brevity, Gee (1990: 150-152) discusses 'primary' discourses as the type of discourses we pick up in face-to-face interaction with intimates and through which we are initially socialised. It is these discourses which form the framework for the acquisition and learning of secondary discourses later in our lives. 'Secondary' discourses, on the other hand, are discourses which are learned through social institutions beyond the family - such as schools, businesses and so on - and provide significantly different frameworks to think, behave and value as compared to primary discourses.

What tends not to be examined in any depth in frameworks like Gee's (1990), though, is the universality of the distinction between primary and secondary discourse and, in particular, its application to both 'oral' and 'literate' cultures. Amongst the Xhosa, for instance, traditional examples of secondary discourse types include the rhetoric employed in various ceremonies like 'releasing the widow' and 'opening a homestead', traditional legal discourse, praise poetry and folk tales, examples of which we shall examine later in this paper. In a different context, another example of a secondary discourse would be, say, a lecture or lesson on mathematics, or a textbook on science. 
These two sets of secondary discourses have the following characteristics in common:

(1) There is, in some sense, a remove between the sender of the discourse and its receiver, the latter in the role of audience.

(2) Some degree of specialisation is required to participate in the discourse, whether as a member of the audience or as the sender.

(3) Certain individuals have the capacity to undertake the role of sender which has involved a type of 'apprenticeship'.

(4) Those individuals, by virtue of their competence in the specialist discourse, are in a position of power.

Distinguishing between primary and secondary discourse shows an obvious parallel with the work of Cummins (for a review, see Bialystok and Cummins, 1991). Cummins analyses language skills in terms of two dimensions: cognitive load, or the degree to which the discourse makes demands on the thought processes and contextual support, or the degree to which the discourse is supported by the parts of the receiver's environment, including the presence of the sender, or the presence of what the sender is talking about. Drawing from Cummins' work, it is clear that one gets discourse competencies of various sorts. For instance, there is the discourse competency which is required for tasks which are cognitively demanding with little contextual support as when reading a complex textbook. At the other extreme, one would have the discourse competency that is required for tasks which are not cognitively demanding and which have plenty of contextual support which is manifest in, for example, informal conversation with a friend. In addition, one would have competencies for the variety of discourses between these extremes. The terms CALF (Cognitive Academic Language Proficiency) and BICS (Basic Interpersonal Communication Skills) as labels for the end points of such overall language proficiency have now become standard terms (see Baker, 1993 for fuller discussion as well as a critique).

Although not generally recognised, such concepts have in fact been implicit in research into the oral tradition for quite some time, especially in work inspired by Lord's research (Lord, 1965). (For an overview, see Gough, 1990 and Kiparsky, 1976: 55-67.) These scholars argue that composers of rhetorical genres in oral societies frequently have to compose often 'original', conceptually and artistically complex works 'on their feet' in front of an audience. Both the cognitive demand necessary to produce the product, and the detachment between audience and performer manifest in such works parallel the BICS/CALP model to some degree. 
It is worth while stressing that Cummins' model draws its inspiration entirely from a Western context and what is labeled as CALP has essentially been interpreted as 'academic literacy' - the specific competencies required to participate in Western academic discourse and acquired through formal learning contexts (for further details see Ballard \& Clanchy, 1988). It is quite clear, though, that CALP does not constitute the only type of secondary discourse universally possible and it is dangerously misleading to think that it does. CALP is simply one manifestation of secondary discourse competence, and it is a manifestation of such competence that is largely based on the type of literacy associated with schooling. It is crucial to bear in mind that while a culture may not display 'academic literacy' or have the abilities to participate in activities demanding such literacy, it does not mean that the culture does not display secondary discourse types.

Various scholars who have done work on the oral tradition have also suggested such a broader interpretation of what we have called secondary discourse. Wallace Chafe $(1981 a, b)$ finds that ritual discourse of the Seneca, a native American group, shows a range of features typically associated with writing. In particular, he finds that the discourse displays conceptual 'integration' and speaker 'detachment', features typically associated with prototypical written discourse. These, he claims, are due precisely to similar contextual factors. Just as in writing, features of integration which include, for example, devices to link clauses together in a tight and compact way, result from the fact that the orators have greater planning time. Features of detachment including, for example, the lack of uptake signals such as 'you follow?,' result from the fact that there is a lack of interaction of the orators with the audience. Olson (1989: 233-245) gives a more recent overview of research which demonstrates similar findings - essentially that secondary discourse types are not necessarily associated with literacy.

\section{Xhosa secondary discourse types}

In the sections that follow, a preliminary examination of selected instances of Xhosa secondary discourse types is presented to exemplify the points raised so far.

\section{Ukukhulula umhlolokazi}

The aim of Ukukhulula umhlolokazi or 'releasing the widow' is to 'effect and make public the woman's status as widow and to incorporate her into society as such' (McAllister, 1990: 134). It displays the use of oratorical strategies on an occasion when members of society are given a chance to reflect on themselves and society and is characterised by a slow style of speech and the use of pauses. Additional features which display the planned and coherent structure of this genre include formulaic 
openings and closings, a characteristic stanzaic structure and sample admonitions.

The formulaic opening and closings, like other Xhosa genres, reveal a clear internal division into structured discursive moves, as illustrated by the translated example which follows:

Opening. It is said that I should produce a few small words for you; it is the usual thing to present words to a person who has been bereaved and is being received by other people. This is referred to as admonishing.

Closing. The words in my mouth are finished now. Perhaps some other man wants to say something.

A second feature of 'releasing the widow' is the stanzaic structure. In the opening and body of this genre, there is a regular 'address + paragraph' stanzaic structure which is marked at the beginning by an address term to the widow concerned. A paragraph then follows which deals with a particular theme:

All right my sister-in-law. It is said that I should produce a few small words for you; it is the usual thing to present words to a person who has been bereaved and is being received by other people. This is referred to as admonishing.

Here it is then sister-in-law. Today these Gcaleka here say they have come to fetch you, seeing that you have been living like this, living abnormally. The time has come for you to go amongst people again. When a person is to go out amongst people she is given words of admonition so that she should not do bad things having been warned.

Now then sister-in-law. We are here so that you should be taken out ...

The following sample admonitions demonstrate the richness of the language and the conveyance of wisdom through metaphorical means.

It does not help to say 'I am rich in many things' if one's heart is impoverished; if the heart is not rich, but impoverished, overgrown with weeds. Many livestock are of no use because a person cannot take them when he goes ....

Do not stop doing such things, for if you do, the paths that lead to this home will become scarce. Because paths are created by people....

You are a mature woman now, you already have daughters-in-law, so you need to be able to stand for yourself. You are a solitary tree, you are a tree that stands for itself....

\section{Intsomi}

An intsomi or folk tale when told by an experienced narrator also typically shows a clear stanzaic structure, with each stanza dealing with a particular episode in the 
story (Gough, 1986). Note the stanzaic structure of the following extract from a Xhosa version of Cinderella: discourse markers (hayi ke, hayi okunene) - given in italics mark the beginning of a new stanza. Clause chaining - given in bold - is marked in this extract by the verb beginning with $w a-$, an agreement marker, past tense, and is used to link clauses within a stanza. The beginning of a new stanza is marked by a break in this clause-chaining pattern and signaled here by the verb beginning in $u$-, an agreement marker, present tense, and ending in - $\mathrm{He}$, a past tense marker. This verb has been underlined in the extract below.

hayi ke uhambile ke umntwana nenqwelo yakhe

wayifihla ke lo mntwana inqwelo etyholweni

wafika apha emdanisweni

wangena ngamandla.

hayi okunene uyithathile le ntombi isangena emnyango

wayixhwila ngoko

wathi nanku umfazi ungenile

wadanisa naye ngobusuku bonke.

No then the child left in her carriage,

$<$ and $>$ she hid the carriage in the bush

$<$ and $>$ she arrived at the dance

$<$ and $>$ she entered openly.

No truly, he (the prince) took the girl as she came in

$<$ and $>$ he swirled her

$<$ and $>$ he said 'Here is my wife, she has entered'

$<$ and $>$ he danced with her the whole night.

Of particular note is that this stanzaic structure appears to be variably present and most marked in more experienced narrators (Gough, 1986). Inexperienced storytellers very often produce far less coherent pieces of work. In particular, they tend to chain together the whole story without the well-planned breaks indicated above.

Izibongo

Izibongo or praise poems produced by experienced iimbongi or oral poets typically display a clear stanzaic structure of address + paragraph (Kashula, 1991). The address is a call to either the subject of the poem or the audience. Following this address is a paragraph which relates to a particular theme. This paragraph typically has the following structure: initial descriptive clauses followed by an argument or 
exhortation. This structure is illustrated by the following stanza from an isibongo. The address is in italics, the descriptive clauses in bold and the argument in roman font:

1. bhotani madun' amahle

2. mathol' onyawo zabezolo

3. iint' ezingoyiki ukufa

4. ezawal' ulwandle zisimelela ngenkanunu nemfakadolo

5. lint' ezaluwel' ulwandle ziqakatha

6. zafika iAfrika zayiphanzisa

7. kuba kwakudiban' entilini

8. yalal' imikhuthuka macal' omabini

9. kodwa imfakadolo yasemlungwini

10 yamnqengqa yamqungquluzis' umAfrika

1. Greetings handsome gentlemen

2. Sons of heroes of old

3. Things that don't fear death

4. Who cross the sea leaning on cannon and breechloader

5. Things who crossed the sea enthusiastically

6. They came to Africa and raped it

7. Because when they met at battle

8. The warriors fell on both sides

9. But the breechloaders of the whites

10 Laid the African low and defenceless.

Note that in the descriptive clauses we find the use of the pattern: noun + relative clause descriptive of the subjects, a feature which is common in this genre. The argument in lines 6-10 includes clauses with logical linkages of cause (because) and contrast (but), which are underlined in the above extract. Another feature of this genre is linkage through structural parallelisms, for example, the repetition of 'Things .... who cross the sea' in lines 3-5.

In general, all these texts have been produced by speakers valued as expert orators in their communities. Their discourse reveals patterns of complex organisation and structuring which is distinct from everyday conversation. In addition, it should be noted that the ability to produce such discourse is variably present in the community. 


\section{Some implications}

A basic point of significance to educators in tertiary institutions is that organisation and structure are not simply the property of Western academic discourses. Rather, we hope we have shown that these features are present in what we have called secondary discourses drawn from traditionally oral sources. Also, the ability to achieve such 'structure and organisation' is variable too. In other words, less accomplished orators produce stylistically poorer speeches.

What becomes clear is that, following Kulick and Stroud (1993), rather than simply focusing on how literacy affects people we need also to examine the effect people have on literacy. A fundamental issue here is that becoming 'literate' or 'academically literate' does not necessarily mean learning the secondary discourse types as if all 'learners' were, by definition empty vessels waiting to be filled. Rather, the development of academic literacy is more about the apprenticeship to Western rhetorical norms and ways of thinking, writing and talking, rather than secondary discourses in general.

As studies in contrastive rhetoric have informed us (see, for example, Leki, 1991), the norms of Anglo-Saxon academic discourses are strongly based on a linear and rapid journey to a point - a point that exists because of the linear journey to it, like the blade to the tip at the end of a dagger. In this context, communication is not only meant to be coherent and cohesive, but also expected to follow what Scollon and Scollon term the C-B-S style (clarity, brevity, sincerity) in that, amongst other things, it has to be 'analytic, original, move rapidly forward, have a unified thesis, avoid unnecessary digressions, and, in essence, present only the most essential information' (Scollon \& Scollon, 1995: 99). They argue that such utilitarian forms of discourse derive from, amongst other things, a particularly Western ideology and process of socialisation. It is an ideology that defines, for instance, humans as rational economic entities, and it is a process of socialisation that stresses the value of formal education and devalues non-formal learning. It is this ideology and such forms of socialisation which underlie the organisational features of academic writing and which is at the heart of learning to be literate in academic contexts.

The situation is a complex one within a context of social change in general, and in South Africa in particular. We may note here that secondary discourse types are dependent on well-established cultural institutions for their transmission and sustenance. It is quite possible, in other words, for such discourse types to be poorly developed while primary discourse types continue to be sustained. One possible cause of this could be through cultural contact. If such contact results in the demise of the indigenous culture, the secondary discourse types will tend to perish with the institutions that sustained them. If, in addition, there is a poor environment for the 
learning of secondary discourse types of the more dominant culture, this will lead to poor development of these secondary discourse abilities as well. It seems to us that this may be the case in parts of South Africa - especially in urban areas - where indigenous secondary discourse types are poorly sustained and where the transmission of the dominant secondary discourse patterns has been weak given the appalling consequences of apartheid education. In the following section, we will examine instances of student discourse in order to explore the kinds of discourse which seem to influence student writing.

\section{An Analysis of Student Writing}

The University of the Western Cape draws its students from traditionally disadvantaged communities. The majority of these are African students who have borne the brunt of the legacy of apartheid in general and apartheid education in particular. The experiences that have shaped the bulk of students' education can be gauged from the following extract from a second-year student's essay on the topic of second-language acquisition.

Problem I experienced with second language was that I was not able to perform and also not good in writing as well. I only speak second language when I was going to the shop by asking prices of the goods. The only thing that motivated me was because I wanted to pass and my teacher used to tell us whoever wants a job one will be forced to speak English...

I was having problem speaking English. I was having an attitude towards second language but there wasn't a choice. I was forced...

I was experiencing some problem with learning second language because in my family English was not a spoken language even by mistake. I was speaking English in the classroom after that I was not speaking because there wasn't a person to speak with. The fact that I was coming from a working class family made me to suffer at school because every subject was taught in English during my Higher Primary [std 3-5]. There were no people through which I can speak the second language with except with my teacher at school.

The worst of all because I was from working class there were no enough source like libraries within the location and even at home there were no English books to read not television unlike middle class and upper class homes whereby one was enjoying the privileges of many be having some magazines and books.

In order to explore the nature of students' writing in more depth, our department collected essays written in both Xhosa, the first language, and English, the second language and language of learning, from students entering university prior to the commencement of the academic year. The following are sample extracts, the first 
written in English on the topic of what students felt to be the best medium of instruction at university, and the second written in Xhosa on the topic of whether they favoured the use of either 'mixed' or 'pure' varieties of Xhosa in public domains. The extracts from these essays are represented here as essentially a clause a line, but otherwise no changes have been made to them.

\section{Example of English L2 essay}

I believe speaking English is just like speaking Xhosa

as long as you can translate anything from English to any language

and if I would say that English should be the only language used

I'd be undermining the other languages

and if I say that each person should be taught in her language

I'd be asking for too much

because the universities should add more lecturers

but then again it's time students and lecturers find an easier way to introducing these languages

because if we do it alone it will take time

as I've already said that these ethnic groups are drifting apart,

each group speaks their own language,

they don't want to interact with the others.

\section{Example of Xhosa (LI) essay}

Masikhumbule ukuba akulula uba umntu asebenzise isiXhosa esisungulekileyo

We should remember that it is not easy for a person to use proper Xhosa

ngoba uqhele ukuthetha isiNgesi esikolweni

because he is used to speaking English at school

ngoku isiXhosa kuzanyanzeleka asixube

so there is pressure for him to mix Xhosa

ngoba kaloku ixesha elininzi akasisebenzisi

as he does not use it for a long time

kwaye umzekelo ukuba uthetha nomntu. osivayo isiXhosa abe engunguye um Xhosa

and for instance if he speaks with a person who understands Xhosa who is not a Xhosa person

soze incoko yenu ibe ibimnandi ukuba usebenzisa isiXhosa esisulungekileyo your conversation could never be enjoyable if you use pure Xhosa

ngoba amanye amagama esiXhosa akazuwava

because he won't understand some Xhosa words

kufuneka ukuze akuve uxube nesiNgesi

it is necessary for him to understand you that you mix with English.

\section{https://repository.uwc.ac.za Page/10}


The questions we asked of this kind of writing included: what discourses do our students' essays display? To what extent does this reflect the oral tradition? Are there other discourses at play here? Most importantly, how do we respond as both linguists and teachers to these discourses?

Perhaps the most striking feature of these essays is their similarity to spoken discourse, with long chains of clauses often making up whole paragraphs. Halliday (1996: 348) notes that spoken language typically tends to be less lexically dense (i.e. has less words per clause) and can accommodate more clauses in its 'sentences' than written language. What we wanted, as academics, was written language. Centred around nominal groups as it is, written language creates a world of 'things and structures, discontinuous, rigid and determinate' (Halliday, 1996: 352). Spoken language is, however, organised around clauses and processes. This ultimately 'creates ... a world that is moving and flowing, continuous, elastic and indeterminate' (Halliday, 1996: 352). As this feature of a spoken flow of ideas was manifest in both the Xhosa and English essays, it reflects a discursive practice that is independent of language per se. It does not appear to be the consequence of writing in an unfamiliar language.

\section{Possible explanations for these patterns}

How can these patterns be explained? Do they reflect a dominance of the primary discourses, or are they a transfer of secondary discourse features? We could ascribe certain practices to particularly Xhosa oratorical features. These include the use of repetition and tautology as forms of embellishment, so that instances like 'the better way or recommendation', and 'to understand or know about this situation' were particularly common in both the Xhosa and English essays. Similarly, the extensive use of hedges such as 'In my opinion', '1 can say' or 'It is said' found in both the Xhosa and English essays, are also a feature of the Xhosa oral tradition where such devices of evidential deference are far more common than in 'Anglo-Saxon' discourse. We may note that both these features are manifest to some degree in the sample of 'releasing the widow' oratory discussed above.

However, we do not believe that they can be transparently explained in terms of transfer of practices from the oral tradition as a possible source of 'alternative' secondary discourse patterns. While clause chaining is a feature of the intsomi narrative genre, the extent of similar chaining as is manifest in the essays tends to be a feature of less experienced or immature narrators of the traditional intsomi genre.

Rather, we were concerned that there were fundamental problems in the educational experience of our learners which had not facilitated in any language 
what Halliday (1996:353) refers to as the 'secondary socialisation', a socialisation that formal educational experience provides, and which, in our terms, facilitates the development of the dominant secondary discourse. According to preliminary research conducted in our department, the practices of Xhosa first-language teaching do not encourage the development of secondary discourses. Xhosa is viewed as the repository of Xhosa culture and values and the curriculum includes a diet of standard grammar taught in decontextualised ways, the reading of classical scholars and an overemphasis on narrative forms of writing, favourite topics including 'A Journey By Train' and 'My School'.

The English class does not appear to be very different, although some students who were interviewed reported that their teachers had used newspapers and magazines in class and had conducted debates. However, the predominant genre to which the students were exposed and had practice in producing in the English language class also appears to have been the narrative.

Perhaps the answer to the question, 'What discourses do our students' essays display' is variable and complex. To some extent these essays display the dominance of the primary discourse, with traces of Xhosa secondary discourses. Secondly, they are almost certainly the result of students' often rather limited proficiency in English and for which reason the relatively simple structure of conjunction + clause + conjunction + clause is preferred. Thirdly, these discourse patterns seem to have been reinforced through the language teaching and learning practices in schools. Taken together, the kinds of patterns reported on above have become a very 'comfortable' way of speaking and writing English.

\section{Other research on student discourses}

Other research on the writing of students at the University of the Western Cape (Leibowitz, 1997) and at another similar tertiary institution (Boughey, 2000) has identified a range of other discourses in student writing beyond that of the oral tradition. These include the discourses of oral debating and the political rally, as well as church-based preaching and biblical rhetoric. Leibowitz offers the following example which displays what she describes as features of church-based rhetoric, written by a student who was a lay preacher and articulate class representative and who had 'an immense access to a variety of Discourses' but who failed the essay in question.

I'm not going to waste much time of narrating the story of who [how?] we were taught to count from one to hundred in English. We started to be taught things like tenses, spellings and homework of English comprehension at standard four, 
that was really a new gospel to us, because nobody helped me at home as my parent were the masters just only in our language.

Of the following extracts from essays which were meant to contrast the philosophies of Locke and Hobbes, Boughey (2000) notes that the first shows the influence of church-based rhetoric and the second traces of popular political rhetoric.

After God created heaven and earth, He gave a man the right to rule the land to rule over the animals. Therefore man have the right to own land and to do everything that is yours. God does not like people who are lazy. God wants us to use our hands e.g. ploughing.

... there must be government representatives at grassroots level. Those representatives will deliver to the government the grievances of the people.

These discourses are not, however, valued in academic literacy and, as scholars such as Gee (1990) have noted, discourses are ideological entities which may marginalise the viewpoints and values central to other discourses. Leibowitz comments critically that for students at our university, included in the opposition between discourses 'are epistemological oppositions, and that many students are unconsciously opposed to the ways of thinking about knowledge and interpretation' which are the givens of university discourse. Of the student who wrote the paragraph above, Leibowitz notes that he failed the essay and that 'he would not be aware how his ways of thinking are in opposition to essay text literacy'. In Street's terms (Street, 1996: 135), the issue is one which places in contact and conflict the 'dominant' and 'marginalised' literacies.

\section{Departmental Responses}

In dealing with this issue, we have engaged in the debate central to social literacy approach which acknowledges a range of literacy practices, in particular local ones, and which emphasises the fundamentally ideological basis of literacy (see Barton, 1994 and Street, 1984, 1996). However, we have had to confront the fact that many of our students' discourses and related literacy practices are the result of an education that inducted them into rituals of literacy in which they were positioned as passive and uncritical recipients of knowledge which they were required to memorise and return to the teacher as best they could. We would argue that acknowledging the discourses and literacies that students bring with them cannot mean imprisoning them in the mediocrity which the educational deprivation of their past confined them to. We have to acknowledge that certain local literacy practices are a direct reflection of policies and a way of life our students had no control over. A literacy practice which is constructed, for instance, on memorisation and rote 
learning of senseless facts can hardly be celebrated or valued.

How have we responded? We have undertaken a range of activities, each reflecting a particular research focus, in an attempt to better understand student writing and how we should respond. The next section reports on two such research projects: the first attempts to engage students in an exploration of their own literacy practices, and the second endeavours to use a discourse and literacy practice which, it appears, they bring with them to university as the basis for a piece of writing.

\section{Two departmental projects}

Both projects were conducted with third-year students during 1999, the first with seven students and the second with the full class of 60 . The first involved a research project which aimed to develop students as researchers of their own literacy practices. The seven students first acted as informants for the lecturer, then replicated the research with three informants each. Data was collected using the following research tools: detailed diaries of literacy events, observations of all the reading and writing texts in their rooms, interviews which covered the informants' language and literacy histories, reading and writing practices at university and their familiarity with different oral traditions. The students also observed and wrote up a description of a storytelling or literacy event, although this proved more difficult to replicate with their informants.

The results were relatively unremarkable. Their practices seemed much as one might expect from any student enrolled in a tertiary institution. Typical events from the diaries included reading academic articles, writing academic essays, taking notes, reading notices around campus, reading, advertisements, signs, 'specials' in town, using calendars, timetables and diaries, reading books, Bible, newspapers and magazines, writing notes for friends to post on their residence door and writing 'wishing cards' to their families. Typical patterns included a predominance of reading over writing, of reading for information or study over recreation, and a predominance of English, although some Xhosa or English/Xhosa mixing occurred for some personal functions, such as letters home. A large proportion of these literacy events happened alone, although some students reported that they did participate in study groups, and some recounted reading and chatting about magazine articles with friends.

A few interesting points which emerged from the interviews were that almost all of the African language speaking students were familiar with storytelling traditions usually passed on by grandmothers, and that a sizeable proportion of the students had begun to learn to read and write before they went to school from mothers and 
older siblings. This latter finding runs contrary to a popular belief that African children generally have no contact with books before they go to school. This was not the case with the small sample we worked with.

However, there was one unexpected outcome, namely that the quality of writing used to report on the observation of storytelling events was surprisingly good! In this activity, students used a framework of questions, such as who tells the story to whom? when? where? what role do the listeners play in the telling? and so on to describe the event. And their writing was more fluent and expressive than the lecturer had previously encountered in their academic writing.

In the second project - an interview - with the full class of 60 students, the lecturer noted a similar improvement in the quality of writing. This project required students to interview a person who they felt had achieved something of note and to record and present the interview as part of a text generation activity in a Materials Development Course. It involved designing the interview questions and conducting, recording, transcribing and editing the interview. The following extract from an interview gives a sense of the quality of writing. This student has managed to capture the style and authenticity of the voice of his interviewee and has created an engaging and lively text (reproduced as the student presented it).

Title: The Man whom they call 'Ironman'

Interviewer: Tell me more about your first professional fight.

Buyisile: That is the fight I cannot forget about, because I fought someone whom 1 never even fought against during amateur and his name is June Siko. The only thing I knew about him was that, he had a strong right punch and with his left hoek, he can put a man down. Another thing I knew about him was that, he had already three fights and all wins, while that was my first professional fight. The fight was scheduled for four rounds. I was very prepared for the fight and I found him prepared too. In round one we caught each other equally but in round two he caught me with his right hand on my chin. (He touches his chin.) As you know that chin can never be fit, I went down and the referee counted for me. The bell rang on count number five and we went back to our corners. After that big punch my knees did not function well and he noticed that and took advantage of me. He knocked me again in round four, that is, the last round and the referee said (raising his hand) 'That is enough', and that was the end of the fight...

Interviewer: Tell me more about your nickname, 'Ironman'.

Buyisile: My nickname.... (he laughs, touching his face with his left hand). I know nothing more except that they say my face does not swell, as if I do not feel the pain when I am fighting. 
Many of the weaker students also performed well on this task - not all to this level, but well enough to pass and for their work to show signs of originality, creativity, enjoyment and interest.

In sum, these two tasks required students to use an analytical framework of questions (storytelling) and a fairly complex and lengthy process of interviewing to arrive at a final product, a piece of writing. It could be argued that both of these are valuable exercises which assist students to interact with the course material, acquire new knowledge and skills and prepare them for the world of work. Importantly, in both the above tasks, students become 'constructors' and 'creators' of knowledge, and not simply passive recipients. To the lecturer concerned, the way students responded represented a welcome change from the standard academic essay in which all too often the theory is regurgitated without much evidence of engagement or understanding.

Based on these experiences, our observation can be summarised as follows: students' writing in English is markedly better, more fluent and more expressive when the task is contextualised, makes use of a narrative genre and requires a more creative and narrative use of language. In terms of the theoretical framework presented earlier in this paper, these projects assisted students to move from primary towards secondary discourse albeit within a cognitively undemanding and contextually supported task. They used a reworking of primary discourses for secondary discourse purposes and, along the way, emphasised the need for structure, coherence and presentation. They validated students' own voices, which Leibowitz and Boughey identified as being in conflict with secondary academic discourses, and used these as a way of constructing and presenting knowledge within an academic task.

\section{Future projects}

In addition to the projects discussed above, we are presently examining alternative ways of developing literacy practices amongst our students as well as deepening our own understanding of these practices. One such possibility relates to the integration of the oral tradition discussed in this paper. Proposals here include the following:

- Students could be exposed to oral secondary discourses of the types mentioned above. Such exposure would be in a programme that emphasises that communicating in a 'special way' is not a feature of Western academic contexts, and that the manifestation of academic literacy is, in fact, only a small facet of an age-old aspect of being human. Historically, however, this aspect has, in many ways usurped alternative secondary forms, and students could be asked to 
reflect critically on this point and to look at the ideological and social contexts that underlie it.

- Texts such as the ones from the Xhosa oral tradition quoted above could also be used in the original languages or in translation and activities could be designed to discover what makes them 'special', different from the ebb and flow of everyday talk and how such differences emerge through the relationship between speaker and hearer and the opportunities to plan. For example, what are the patterns of organisation present in these texts? How are ideas grouped and structured? More generally, what makes these texts cohesive and coherent?

- In addition to these linguistic activities there could also be a focus on the kind of knowledge present in these texts, how this knowledge has been constructed and is being transmitted and how this 'knowledge' is different from that found in academic contexts.

- Students could be asked to collect or produce their own secondary texts. This could serve to highlight the role of secondary discourses in their own communities and also possibly the extent to which these have been affected by Western forms. Here the student as researcher and actor comes into play.

- Students could be asked to translate the texts themselves. This task would serve the dual purpose of discovering the complex organisation as well as highlighting the difficulties of translating discourse-specific features. Such an exercise would allow the specific discovery of possible gaps in second language abilities which might otherwise prevent students from giving form to meaning.

- At a more advanced level one could 'interface' different genres, so that, for example, the hortatory texts of izibongo could be taken over into a report. In this way, students could use the content of a praise poem but with a different structure.

A second project for future investigation includes an interrogation of the discourse practices of 'classical' academic writing that structures us as academics at a university in transition. The following quotation, for instance, comes from our university's new academic plan:

The following directives, formulated in response to both internal and external imperatives, form the foundation stones which guide the framework for academic planning.

The impersonal, detached and dense style, so valued in academic discourse, certainly does not lead to great clarity. Who, for instance, has formulated the directives? How can directives form 'foundation stones' and how can foundation stones 'guide' a framework? Can this in any way be said to be a preferred and empowering style? Mimicking formal academic writing that often obscures rather than clarifies does not 
seem to be a terribly worthy academic goal, and developing clarity of expression and lexico-grammatical capacities as a resource for allowing the expression of meaning is a fundamental task.

\section{Further implications}

What, then, are the implications of this for academic curricula and assessment practices? We propose that we (and here we mean, 'we, the academic community') should broaden our more traditional conceptions of what it means to be academically literate and include in our academic curricula tasks which:

(1) develop students' awareness of a range of secondary discourse types, including those from oral traditions; and

(2) utilise writing tasks which draw on a range of genres, specifically the more narrative and creative ones. We are not referring to using these tasks as a starting point only, which is already common practice in many foundation or entry level courses, but to the inclusion of such tasks right through the undergraduate years. Neither are we referring to straight, imaginative 'creative' writing. Rather, we are talking about tasks which require students to demonstrate understanding of theoretical concepts or models through the employment of a more narrative or creative mode. This does not mean dressing up a traditionally academic task in a narrative guise. Rather, the very nature of the task should require students to adopt a creative or narrative mode as the most appropriate response.

This has implications not only for the way we teach students, but also, crucially, for the way in which we assess them. However, we are not advocating a shift away from the need to develop more traditional academic forms of writing, because we believe that for the foreseeable future, given our position globally and economically, South African students will be advantaged by the ability to write in relatively Standard English in a relatively detached, depersonalised, integrated style, as this will enable them more easily to access economic and political opportunity and, if necessary, to challenge these discourses of power. The development of these Western academic discourses of power must remain a goal, although not the only one to the exclusion of others.

\section{What can be gained from this broadening of the notion of 'academic literacy'?}

We suggest that it is a way of: 
- getting away from the practices of rote learning, which is typically reflected in students' essays through the clumsy 'chunking' of source material, usually without any linking ideas or any reference to the source of the 'chunk' and not much evidence that the source material has been 'processed' and integrated into students' own frameworks of knowledge;

- developing within students a sense that they can be 'producers' and not just 'consumers' of knowledge;

- motivating students and turning around a sense of failure for both staff and students;

- recognising and building on discourses that students bring with them to university;

- developing fluent and carefully planned writing in English, which after all, must be one of the goals of English-medium tertiary curricula in South Africa.

\section{Conclusion}

In this paper we hope to have shown that secondary discourses are not necessarily associated with literacy, and that the oral tradition provides a rich set of secondary genres. Acknowledgement of this can provide a useful background for understanding students' discursive practices in tertiary contexts. In addition, other literacy and discourse practices shape student writing, including alternative 'local' literacy practices which are shaped by and acquired in specific social contexts and which may be in opposition to the dominant discourses demanded by universities. Acknowledgement of the discourses students bring with them to university may go a long way in explaining students' writing, but it does not necessarily provide guidelines for a way forward to providing students with the 'powerful' discourses and literacies they will require and to which they aspire. In this respect, this paper has presented a number of possible strategies, while emphasising the need, simultaneously, to take a critical view of the power of academic literacy in particular.

\section{Acknowledgements}

The financial assistance of the National Research Foundation and the Anglo American Corporation is gratefully acknowledged. The views expressed here are entirely those of the authors. All errors and shortcomings remain their own.

\section{Correspondence}

Any correspondence should be directed to Ms Zannie Bock, Department of Linguistics, University of the Western Cape, Private Bag X17, Bellville 7535, South Africa (zbock@uwc.ac.za). 


\section{References}

Baker, C. (1993) Foundations of Bilingual Education and Bilingualism. Clevedon: Multilingual Matters.

Ballard, B. and Clanchy, \}. (1988) Literacy at the university: An 'anthropological approach'. In G. Taylor, B. Ballard, V. Beasley, H.K. Bock, J. Clanchy and P. Nightingale (eds) Literacy by Degrees. Milton Keynes: The Society for Research into Higher Education and Open University Press.

Barton, D. (1994) Literacy: An Introduction to the Ecology of Written Language. Cambridge: Blackwell.

Bialystok, E. and Cummins, J. (1991) Language, cognition and the education of bilingual children. In E. Bialystok (ed.) Language Processing in Bilingual Children (pp. 222-232). Cambridge: Cambridge University Press.

Boughey, C. (2000) Alternative constructions of language related problems. Unpublished MS, Rhodes University, Grahamstown.

Chafe, W.L. (1981a) Differences between colloquial and ritual Seneca or how oral literature is literary. Reports from the Survey of California and Other Indian Languages. Vol. 1 (pp. 131-145).

Chafe, W.L. (1981b) Integration and involvement in speaking, writing and oral literature. In D. Tannen (ed.) Spoken and Written Language: Exploring Orality and Literacy (pp. 121-145). New Jersey: Ablex.

Gee, J. (1990) Social Linguistics and Literacies. London: Falmer Press.

Cough, D.H (1986) The Xhosa intsomi: Issues in the production and linguistic categories of discourse. PhD thesis, Rhodes University, Grahamstown, South Africa.

Gough, D.H (1990) Oral formula and oral tradition: Problems and prospects. In H.C Groenewald (ed.) Oral Studies in South Africa (pp. 27-39). Pretoria: HSRC Publications.

Halliday, M.A.K. (1996) Literacy and linguistics: A functional perspective. In R. Hasan, and G. Williams (eds) Literacy in Society (pp. 339-371). London: Longman.

Kashula, R. (1991) Tradition and innovation in Xhosa izibongo. In E.R. Sienaert, A.N. Bell and M.Lewis (eds) Oral Tradition and Innovation. University of Natal: Oral Documentation and Research Centre.

Kiparsky, P. (1976) Oral poetry: Some linguistic and typological considerations. In B.A. Stoltz and R.S. Shannon (eds) Oral Literature and the Formula (pp. 55-67). Ann Arbor: University of Michigan Press.

Kulick, D. and Stroud, C. (1993) Conceptions and uses of literacy in a Papua New Guinean Village. In B. V. Street (ed.) Cross Cultural Approaches to Literacy (pp. 30-61). Cambridge: Cambridge University Press.

Leibowitz, B. (1997) Work in Progress: Reflections on a university writing assignment in the light of the NQF and OBE. Unpublished paper, South African Applied Linguistics Association Conference. 
Leki, I. (1991) Twenty five years of contrastive rhetoric: Text analysis and writing pedagogies. TESOL Quarterly 25 (1), 123-145.

Lord, A.B. (1965) The Singer of Tales. New York: Athenaeum Press.

Lucy, J. A. (1992) Language Diversity and Thought: A Reformulation of the Linguistic Relativity Hypothesis. Cambridge: Cambridge University Press.

McAllister, P. A. (1990) 'Releasing the widow' - Beer drink and oratory and status change in Willowvale, Transkei. In H.C. Groenewald (ed.) Oral Studies in South Africa (pp. 101-127). Pretoria: HSRC Publications.

Olson, D. (1989) On the language and authority of textbooks. In S. De Castell, A. Luke and C. Luke (eds) Language, Authority and Criticism (pp. 233-245). Sussex: The Falmer Press.

Scollon, R. (1995) Intercultural Communication: A Discourse Approach. Oxford: Blackwell.

Street, B.V. (1984) Literacy in Theory and Practice. Cambridge: Cambridge University Press.

Street, B.V. (1996) Preface. In M. Prinsloo and M. Breier (eds) The Social Uses of Literacy: Theory and Practice in Contemporary South Africa (pp. 1-9). Cape Town: SACHED Books and John Benjamins Publishing. 